\title{
Transformações em torno do fenômeno da violência homicida no estado de Alagoas'
}

\author{
Emerson Oliveira do Nascimento \\ Doutor em Ciência Política pela Universidade Federal de Pernambuco \\ Professor da Universidade Federal de Alagoas \\ emersondonascimento@yahoo.com.br
}

\begin{abstract}
Resumo Embora Alagoas ocupe a posição de estado mais violento do Brasil desde 2006, poucos esforços têm sido empreendidos para explicar e compreender a constituição desta realidade. A explosão dos percentuais de violência homicida registrados em Alagoas na última década tem sido, com frequência, associada, ora à ideia de um resíduo histórico da violência "fundante" da província no século XIX, ora à ideia de uma cultura da violência que distinguiria, sobremaneira, o alagoano. Acreditamos que estes argumentos perdem de vista a particularidade do problema, pois enfatizam explicações estruturalistas que, ao longo do tempo, pouco contribuíram para a formação de componentes cognitivos que fomentassem a concepção e a implementação de planos ou programas de segurança no estado. Recorremos aqui aos conceitos de acumulação social da violência e sujeição criminal, de modo a reafirmar a constituição de uma interpretação menos historicista e mais sociológica do referido fenômeno. Argumentamos, ainda, que, no caso alagoano, este processo tem disseminado - talvez como em nenhum outro lugar do Brasil - a produção de um discurso que negligencia, nos planos simbólico e prático das relações de Estado, o desenvolvimento de políticas públicas de segurança preventivas ou compensatórias.
\end{abstract}

Palavras-chave: acumulação social da violência, sujeição criminal, homicídios, Alagoas.

\section{Apresentação}

A lagoas é o estado que apresenta os maiores percentuais de violênA cia homicida do Brasil. Nosso objetivo aqui foi, primeiramente, a partir das situações que envolvem homicídios intencionais em Alagoas, construir uma representação cartográfica da vitimização por homicídio na capital e Região Metropolitana de Maceió (RMM); em seguida, identificar os padrões de interação que explicam as condições necessárias e suficientes para o desfecho letal desses casos. Para alcançar esse objetivo, elaboramos uma representação gráfica dessa realidade a partir de uma coleção de dados vetoriais oriundos do Núcleo de Estatística e Análise Criminal da Secretaria de Segurança Pública do Estado de Alagoas (SSP-AL) e dados alfanuméricos do Sistema de Informação de Mortalidade do Ministério da Saúde (SIM-MS) e do Instituto Brasileiro de Geografia e Estatística (IBGE). Depois desta visualização da

1. Parte dos dados sistematizados e analisados neste artigo é oriunda de um projeto coordenado pelo autor e financiado pelo Conselho Nacional de Desenvolvimento Científico e Tecnológico (CNPq), intitulado "A Organização Social do Espaço e a Violência Letal na Região Metropolitana de Maceió". 
dinâmica espacial das mortes violentas em Alagoas, concentramos nossa atenção na refutação das principais hipóteses explicativas em curso sobre o problema da violência homicida do estado de Alagoas. Destacamos a particularidade e a relativa novidade do problema da violência homicida no estado e propusemos uma via alternativa de interpretação para o problema, como forma de contrapor as explicações apoiadas em argumentos historicistas. Finalmente, recorremos aos conceitos de acumulação social da violência e sujeição criminal (Misse, 1999, 2002, 2006, 2008a, 2008b) como proposições eminentemente sociológicas capazes de superar os limites das explicações centradas em lógicas exclusivamente residuais (Freitas; Mello; Almeida, 2009; Lindoso, 1981, 2000, 2005; Verçosa, 2001; Apratto, 2007).

\section{Metodologia}

A violência urbana no Brasil aparece hoje como um dos principais problemas a ser enfrentados, seja pela população de maneira geral, seja pelos gestores públicos. Na sua grande maioria, estes percentuais concentram-se nas regiões metropolitanas de algumas capitais, com destaque para o crescimento relativamente recente destes percentuais no Nordeste do país. Além de toda a sensação de insegurança que toma conta da sociedade civil e da mídia, e de todo o terror social que pode emergir daí, há um tipo de indicador concreto, adequado e perfeitamente comparável para avaliar a dimensão dessa violência urbana: o crime de homicídio.

Não desprezamos o fato de que este não é o único indicador possível, é claro; todavia, acreditamos que seja o indicador mais seguro para mensurar a dimensão da violência urbana, tendo em vista que tais ocorrências despertam não só uma maior reação moral e institucional, mas também são menos passíveis de subnotificação; sobretudo quando pensamos em outros tipos de violência, como estupros, agressões físicas não letais ou crimes contra o patrimônio. Nesse sentido, considerando esse indicador e os relatórios de agências internacionais, o Brasil figura como um dos países mais violentos do mundo, ocupando hoje a sétima posição no ranking promovido pela Organização Mundial da Saúde.

Propor um debate sobre homicídios significa admitir, desde já, a urgência dessa questão como legítima demanda social. Em Alagoas, o tema da se- gurança pública é hoje um dos aspectos-chave da questão social, que se torna cada vez mais complexa. Nos últimos anos, o quadro trágico da violência no estado - em particular, os homicídios - tem ganhado destaque nos noticiários locais e nacionais, suscitando polêmicas nos meios acadêmicos e diferentes reações na sociedade alagoana. Para dar conta do fenômeno, reformulam-se antigos conceitos ou forjam-se novos, antes mesmo de se mensurar os impactos dessa violência letal ou conhecer as reais dimensões da sua escalada.

Os índices de violência no estado, especialmente os relativos a homicídios, vêm aumentando de forma vertiginosa desde o final dos anos $1990 .^{2}$ Segundo relatório da Organização das Nações Unidas para a Educação, a Ciência e a Cultura (Unesco), com dados do período de 1989 a 1998, Alagoas figura entre os estados brasileiros com maior incidência de homicídios entre a população em geral e entre os jovens. A análise da dinâmica dos homicídios na região, com base em séries históricas, e as formas de enfrentamento do problema, tanto no plano individual e coletivo quanto no político e institucional, mostram que, apesar de desolador, o fenômeno é relativamente recente. Nesse sentido, a atuação (no passado) de grupos de extermínio, ou mesmo os percentuais de impunidade registrados no estado, menos que causas do atual estágio do problema, são agravantes desse cenário.

Este artigo abordará, de forma preliminar, as interconexões entre crime e cidade no estado de Alagoas, a partir dos dados e indicadores necessários para a compreensão dessas dimensões. Nesse sentido, serão exploradas as taxas de homicídio e sua relação com a dinâmica contextual das comunidades urbanas da capital e da região metropolitana do estado, visando esmiuçar e desagregar territorialmente e temporalmente essas dimensões. Interessa-nos, neste momento, averiguar em que locais e horários os crimes ocorreram; qual o sexo e a faixa etária das vítimas, e qual o tipo de arma utilizada nesses crimes.

Diante das dificuldades de condensar mapas e bancos, muitas vezes registrados a partir de perspectivas institucionais ou particulares diferentes, tentamos, de forma exploratória, montar o quebra-cabeça da violência em Alagoas a partir daquelas que devem ser as melhores informações disponíveis. A saber, os dados oferecidos por instituições públicas de pesquisa e gestão de Estado, tanto federais, quanto estaduais.

Os softwares utilizados para a análise dos sistemas de informação aqui consultados foram o Excel $^{\circledR}$ e o

2. A partir de 1999, em Maceió, a violência (em termos de homicídios) aumentou de maneira significativa. Nesse ano, a capital do estado registrou uma taxa de homicídios de 30,9 para cada 100 mil habitantes, passando para 98 cada 100 mil em 2006 , segundo dados do Ministério da Saúde e do Ipeadata. Este crescimento na taxa de homicídios pode ser percebido em função do título que a capital acabou por receber "a capital mais violenta do Brasil" -, tendo em vista que Maceió passou a ocupar posição de destaque no ranking de homicídios das capitais brasileiras (Cerqueira, 2013). 
IBM SPSS $®$, para as análises estatísticas e para gerar os gráficos, o que nos possibilitou a criação de um perfil descritivo das vítimas de homicídios na Região Metropolitana de Maceió (RMM), englobando, entre outras informações, o sexo, idade e raça das vítimas. No que diz respeito à análise espacial, os GIs (Geographic Information System) utilizados foram o TERRAVIEW ${ }^{\circledR}$ e o ARCGIS ${ }^{\circledR}$. Esses programas nos possibilitaram a constituição de uma representação visual da dispersão das ocorrências de violência homicida no estado de Alagoas, através dos dados fornecidos pela SSP-AL, com prioridade para abordagens keynesianas, as quais chamam a atenção para a dimensão circunscrita e territorializada que marca fortemente a dispersão das ocorrências nas áreas mais precárias e vulneráveis da capital e sua região metropolitana.

Devemos mencionar aqui, ainda, o problema da qualidade dos dados disponibilizados pelo SIM -MS. O primeiro problema encontrado, de conhecimento geral, é o alto grau de subnotificações em algumas partes do registro do banco do sistema; o que se mostrou um desafio durante n nossa coleta, visto que encontramos uma grande porcentagem de subnotificações nos campos escolaridade e ocupação das vítimas de homicídio no estado de Alagoas. Por isso, a análise desses dados foi inviabilizada nesse primeiro momento. ${ }^{3}$

O problema seguinte foi encontrado no banco de dados fornecido pela SSP-AL. A despeito da importância dos dados fornecidos por essa secretaria, o fato de estes não estarem devidamente organizados, de modo a que pudéssemos consultá-los a partir dos setores censitários, inviabilizou o isolamento de algumas regiões durante a construção cartográfica dos mapas temáticos. ${ }^{4}$

A partir das indicações das áreas que apresentam as mais altas taxas de risco de morte violenta na região, partimos para o esboço de uma compreensão da dimensão contextual das comunidades urbanas da capital do estado e da RMM, considerando, para isso, tanto a trajetória de formação e ocupação desses bairros, quanto os fatores individuais associados à prática do homicídio nessas áreas, por meio da aná- lise das circunstâncias e dos fatores motivadores da ação homicida.

Nesta seção faremos uso das entrevistas transcritas e compiladas de agentes da segurança pública do estado (policiais, delegados, escrivães e agentes), bem como de fontes documentais que consultamos para a compreensão de determinadas dinâmicas de organização social e sociabilidade que nos propomos interpretar a partir dos conceitos presentes nos escritos de Michel Misse (acumulação social da violência e sujeição criminal).

\section{Caracterização do padrão de homicídio em Maceió e Região Metropolitana}

Os principais estudos sobre padrões de homicídios no Brasil são recentes. Além dos estudos publicados em periódicos especializados, três livros e duas teses reúnem as principais contribuições elaboradas até agora (Cruz e Batitucci, 2007; Soares, 2008; Beato, 2012; Cerqueira, 2010; Manso, 2012). No plano analítico, são conhecidos os trabalhos que relacionam homicídios e tráfico de drogas (Zaluar, 1994; Misse, 2006). No estado de Alagoas, a despeito dos vários estudos já realizados e das altas taxas de violência letal apresentadas, ainda não há trabalhos deste tipo. Nesse sentido, o que apresentaremos agora é o resultado da parte preliminar da pesquisa em andamento: a caracterização do fenômeno da violência homicida em Alagoas.

Alagoas é o estado que registrou o maior número de homicídios no ano passado, segundo a nona edição do Anuário Brasileiro de Segurança Pública ${ }^{5}$ divulgada em outubro do ano passado pelo Fórum Brasileiro de Segurança Pública (FBSP). ${ }^{6}$ Foram registradas 61,9 mortes para cada grupo de 100 mil habitantes, ${ }^{7}$ o que representa, a partir de números absolutos, o registro de pelo menos 5 crimes violentos letais intencionais por dia no estado durante o ano de 2014. O resultado repete, mais uma vez,

3. Pretendemos suprir essa lacuna fazendo uso dos dados socioeconômicos provenientes do Instituto Brasileiro de Geografia e Estatística (IBGE) para 2010

4. No presente momento, a SES-AL já resolveu este impasse, substituindo, como ferramenta de análise espacial, o Google Earth pelo ARCGIS, ampliando em muito a capacidade analítica das ferramentas de mapeamento criminal para o estado de Alagoas.

5. O anuário reúne dados dos órgãos de segurança pública dos estados e do governo federal, além de informações do Instituto Brasileiro de Geografia e Estatísticas (IBGE), do Ministério da Saúde e do próprio FBSP. Este ano, o documento dividiu os estados por categorias de qualidade da informação fornecida, porque os sistemas de informação são abastecidos de forma diferenciada por cada unidade da federação.

6. É importante realçar que, de acordo com o Anuário Brasileiro de Segurança Pública de 2015, Alagoas não só é o estado que apresenta as maiores taxas de homicídio, mas também um dos estados com as estatísticas criminais mais confiáveis para os últimos três anos, apresentando alta qualidade nas informações sobre homicídio e vitimização e no registro destas informações nos órgãos competentes.

7. Os índices recomendados pela Organização das Nações Unidas (ONU) preveem o máximo de 10 homicídios anuais por 100 mil habitantes. 
o ranking do último levantamento, quando Alagoas também ficou em primeiro lugar, seguido por Ceará e Espírito Santo - que registraram, respectivamente, 47,9 e 40,7 mortes por 100 mil habitantes - e Goiás e Sergipe, ambos com a taxa de homicídio de 40,1 para o ano de 2013.

Segundo dados do SIM-MS, nas últimas três décadas a violência cresceu 420\% em Alagoas. Só na última década, esse crescimento foi de 117\%. Esse fenômeno tem se tornado um problema alarmante, visto que a dinâmica dos homicídios no estado extrapola o que é prescrito, tanto no cenário nacional quanto no regional. Em 1999, Maceió era a $14^{a}$ capital mais violenta do Brasil, atingindo o título macabro de "capital mais violenta", pela primeira vez, a partir de 2006, e chegando ao expoente máximo dessa violência homicida em 2010, quando foi registrada uma taxa de homicídios de 110,1 para cada 100 mil habitantes, nessa capital. Apesar de alarmantes, esses dados são relativamente novos, visto que desde 1980 essa taxa situava-se no patamar de 25 homicídios por 100 mil habitantes, crescendo de forma drástica no da década de 1990. Contudo, é incorreto dizer que Alagoas seja o líder em violência letal quando são consideradas outras taxas de mortalidade, como os suicídios e os acidentes de trânsito.

O gráfico 1 mostra que as taxas de acidentes de trânsito, homicídios e suicídios no Brasil, para os anos de 2006 a 2011, giram em torno de 20, 26 e 5 ocorrências, respectivamente, para cada grupo de 100 mil habitantes. Os gráficos 2 e 3 mostram que as taxas para acidentes de trânsito e suicídios, no Nordeste e em Alagoas, são relativamente similares ao padrão nacional. Alagoas só destoa sensivelmente do padrão nacional e regional no que diz respeito, especificamente, à taxa de homicídios.

Gráfico 1 - Taxa de mortalidade específica para acidentes de trânsito, homicídios e suicídios no Brasil (2006-2011)

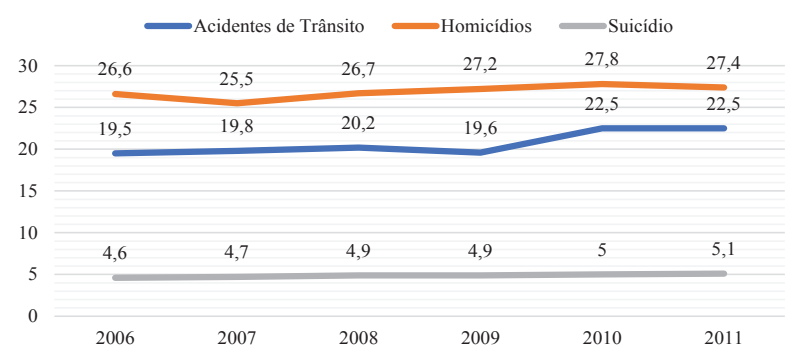

Fonte: MS/SIM

Elaboração dos autores

Nota: taxa por $100 \mathrm{mil}$ habitantes.
Gráfico 2 - Taxa de mortalidade específica para acidentes de trânsito, homicídios e suicídios no Nordeste (2006-2011)

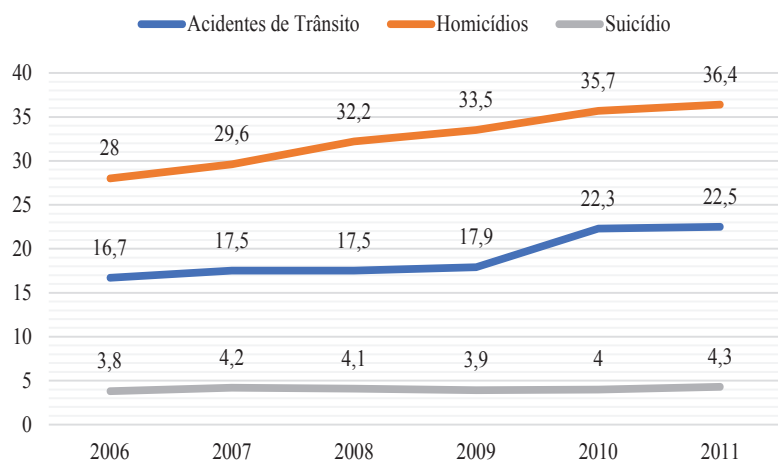

Fonte: MS/SIM

Elaboração dos autores.

Nota: taxa por 100 mil habitantes

Gráfico 3 - Taxa de mortalidade específica para homicídios, suicídios e acidentes de trânsito em Alagoas (1990-2010)

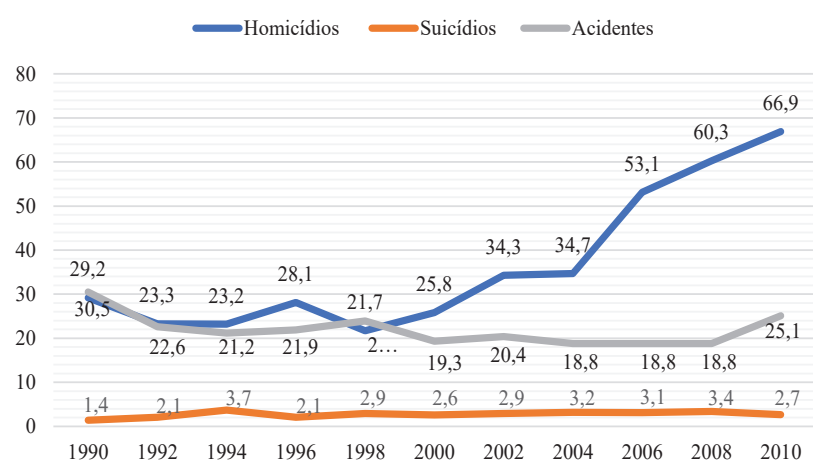

Fonte: MS/SIM

Elaboração dos autores.

Nota: taxa por 100 mil habitantes

Em termos de violência letal, Alagoas e a RMM destoam da média brasileira apenas no registro dos incidentes que envolvem homicídios, que é o foco da nossa atenção no presente momento. Nos gráficos 4 e 5, apresentamos as taxas de mortalidade específica para homicídios na RMM e na capital, isoladamente.

Gráfico 4 - Taxa de mortalidade específica para homicídios na Região Metropolitana de Maceió (2006-2011)

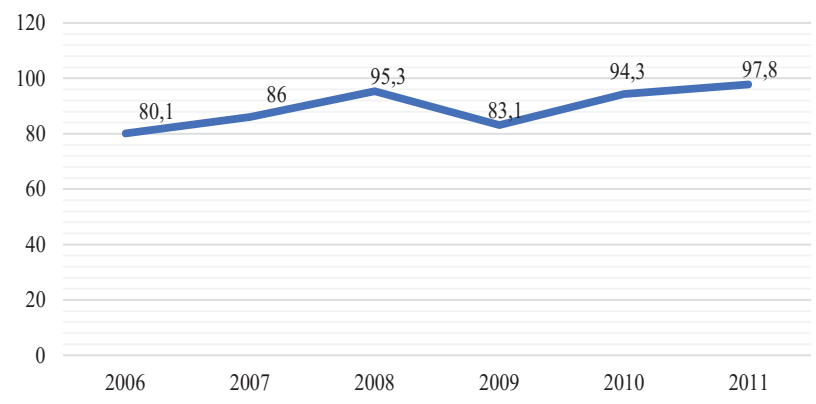

Fonte: MS/SIM

Elaboração dos autores.

Nota: taxa por $100 \mathrm{mil}$ habitantes 
Gráfico 5 - Taxa de mortalidade específica de homicídios em Maceió (2006-2011)

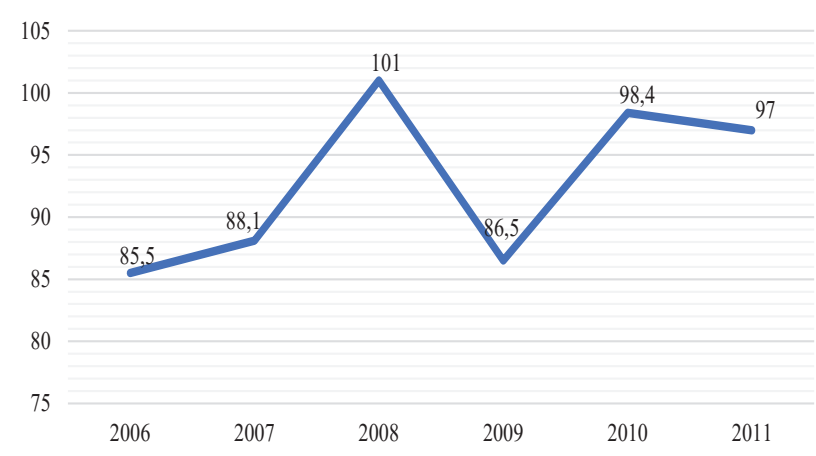

Fonte: MS/SIM

Elaboração dos autores.

Nota: taxa por 100 mil habitantes

Quanto ao número de óbitos por homicídio segundo o local de residência, as taxas observadas referem-se principalmente à RMM, sendo o município de Pilar aquele que apresenta os maiores índices - mesmo entre os municípios brasileiros -, segundo dados do Instituto de Pesquisa Econômica Aplicada (IPEA). Em sequência, apresentamos o Gráfico 6, no qual comparamos as taxas de mortalidade específica para homicídios no Brasil, no Nordeste e na RMM, no período entre 2006 e 2011.

Gráfico 6 - Taxa de mortalidade específica para homicídios na Região Metropolitana de Maceió, Nordeste e Brasil (2006-2011)

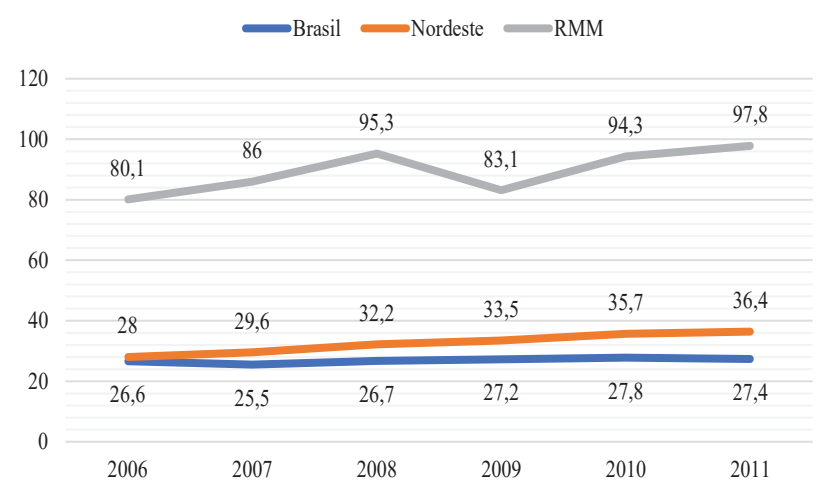

Fonte: MS/SIM

Elaboração dos autores.

Nota: taxa por 100 mil habitantes

Segundo dados da SSP-AL, no ano de 2012, do total geral de 1.755 homicídios, 673 foram registrados na faixa etária dos 15 aos 24 anos. Os dados empíricos dos homicídios na capital, segundo grupos de sexo (Gráfico 7), cor (Gráfico 8) e idade (Gráficos 9 e 10), confirmam as tendências do perfil nacional para essas categorias. As vítimas de homicídios são predominantemente homens, jovens - com idade em torno de 20 anos - e de cor negra ou parda.
Gráfico 7 - Taxa de mortalidade específica por sexo para homicídios em Maceió (2006-2011)

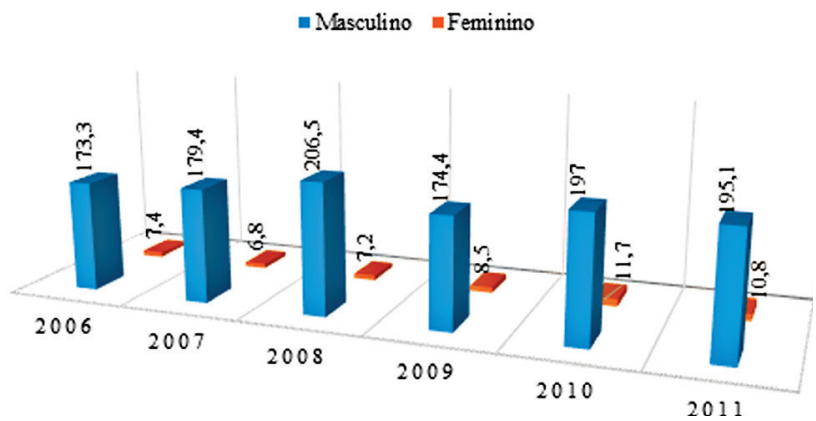

Fonte: MS/SIM

Elaboração dos autores.

Nota: taxa por 100 mil habitantes

Gráfico 8 - Taxa de mortalidade específica por cor da pele entre as vítimas de homicídio no estado de Alagoas em 2010

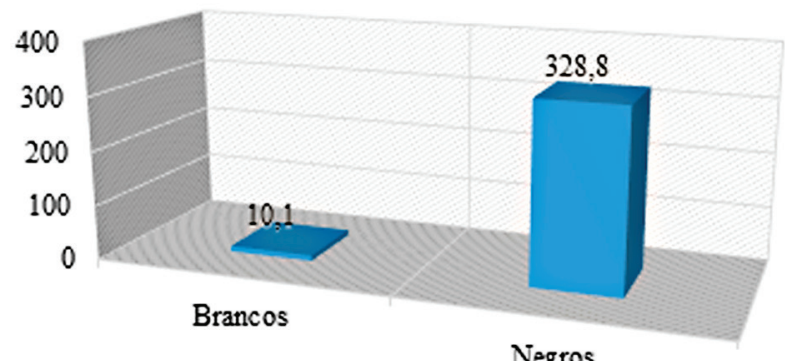

Fonte: MS/SIM; IBGE/PNAD

Elaboração dos autores.

Nota: taxa por 100 mil habitantes

Gráfico 9 - Taxa de mortalidade específica por faixa etária para homicídios em Maceió (2006-2011)

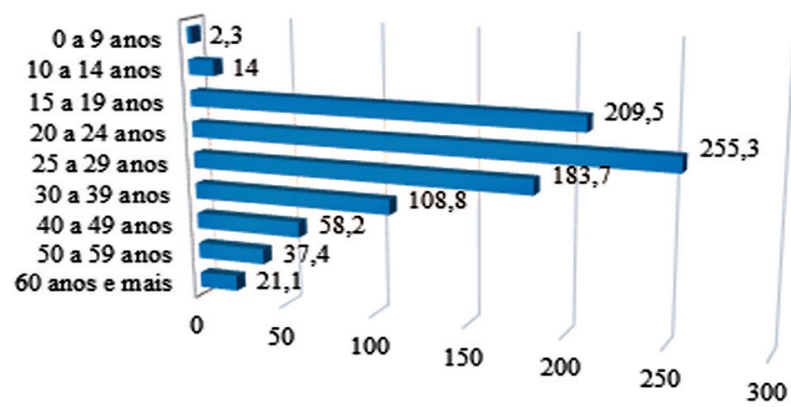

Fonte: MS/SIM; IBGE/PNAD

Elaboração dos autores.

Nota: taxa por 100 mil habitantes

Gráfico 10 - Taxa de mortalidade específica por sexo e faixa etária para homicídios em Maceió (2006-2011)

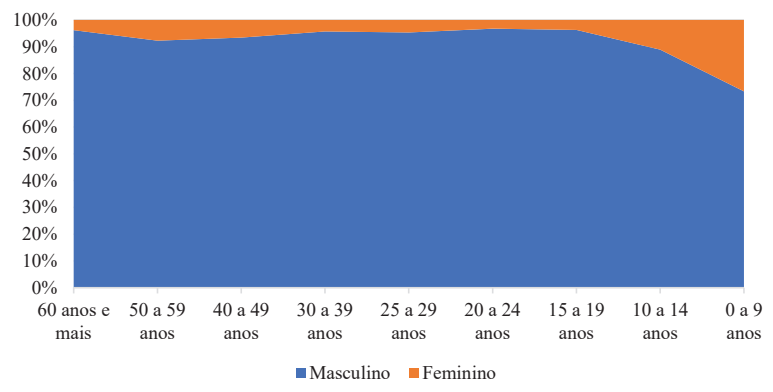

Fonte: MS/SIM; IBGE/PNAD

Elaboração dos autores.

Nota: taxa por 100 mil habitantes 
Zanotelli (2003), com base nos estudos de Augustin Berque, ressalta a importância de se conhecer os territórios do crime - sua distribuição socioespacial -, entendendo que há uma paisagem produzida localmente pela violência nas aglomerações urbanas. Com relação aos elementos contextuais associados a esses homicídios em Alagoas, os dados disponíveis no Sistema de Informação de Mortalidade do Ministério da Saúde apontam uma predominância destes incidentes na via pública, todavia, dado o percentual de registro de homicídios que ocorreram em local desconhecido (87,9\%), a informação não parece ser muito segura. ${ }^{8}$

Mapa 1 - Densidade de homicídios em Maceió e RMM (2012-2014)

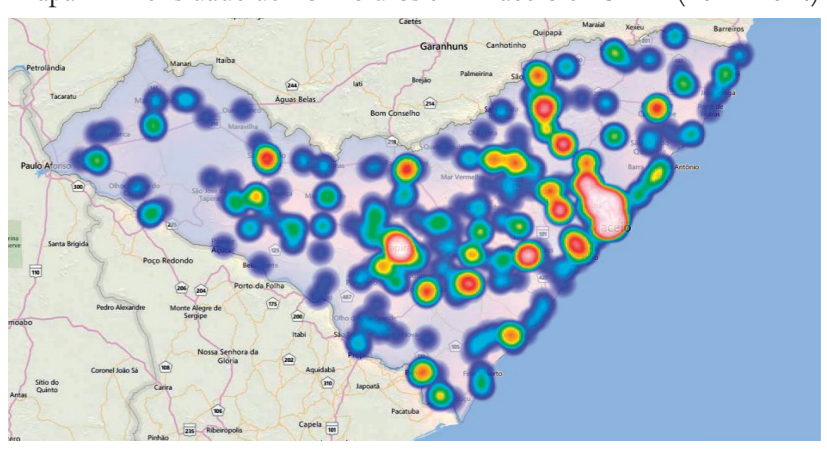

Fonte: SSP-AL

Elaboração dos autores.

Como podemos observar no mapa temático de densidade, elaborado a partir das ocorrências georreferenciadas pela SSP-AL no período de 2012 a 2014, a concentração maciça de homicídios dá-se majoritariamente na capital do estado e na RMM (onde predomina a maior mancha criminal do mapa); depois, nas cidades de Arapiraca e Palmeira dos Índios. Subsequentemente, nas cidades mais populosas do estado depois de Maceió, que também sofreram grandes transformações urbanas nas duas últimas décadas.

Agora, recortando-se a capital do estado e sua região metropolitana da nossa amostra e ampliando-se sua visualização, podemos observar que o crime de homicídio não se distribui homogeneamente pela cidade. Na verdade, possui áreas mais críticas de concentração, sobretudo a região da área lagunar, a qual concentra indicadores sociais bastante negativos e configurou-se, num passado recente, como área de resistência e embate permanente, com a remoção de comunidades de pescadores que sobrevivem da pesca de peixes e crustáceos para sobrevivência.
A área litorânea da cidade é praticamente intocada pelos crimes de homicídio, à exceção do bairro de Jacintinho, que se configura como exceção. O Jacintinho localiza-se próximo à área turística da cidade e congrega tanto habitações de melhor padrão, quanto habitações subnormais. Trata-se de um bairro gestado à margem das principais praias da cidade, onde concentra-se a maior parte dos profissionais prestadores de serviço, em geral, para a clientela da área nobre (Carvalho, 2012).

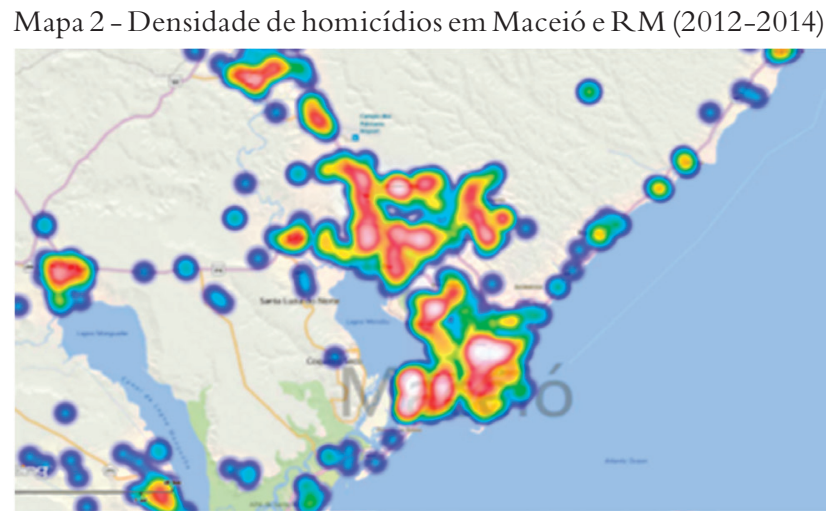

Fonte: SSP-AL

Elaboração dos autores

Quanto à temporalidade dos homicídios, a exemplo da tendência nacional, a maioria ocorre nos fins de semana, com uma evolução significativa dos casos a partir da sexta-feira. A relativa previsibilidade das ocorrências deve ser objeto de investigação, visando a adoção de medidas preventivas específicas de políticas públicas. Sabe-se, a partir dos bancos consultados, que a maior parte das ocorrências aconteceu entre as 19 horas e as 22 horas, com prevalência para os dias de sábado e domingo, e que a arma de fogo foi o principal instrumento utilizado (pelo menos em $82,2 \%$ dos casos). ${ }^{9}$

No tocante à sazonalidade mensal, não se observa nenhuma tendência marcante no período analisado. De modo geral, registra-se um número elevado de óbitos em todos os meses do ano. Há pouca variação entre as diferentes estações do ano: a maior taxa foi no verão $(26,6 \%)$ e a menor, no inverno $(23,6 \%)$; primavera e outono apresentam índices quase iguais (respectivamente, 25,4\% e 24,4\%).

A percepção de que os óbitos por homicídio se constituem somente a partir de um conjunto de individualidades em interação é imperfeita, e limita a compreensão do fenômeno como um todo relativa-

8. Sobre a questão da localização exata dos incidentes de homicídio em Alagoas, é importante realçar que muito em breve poderemos ter dados mais robustos sobre esse item, pois a SSP-AL tem investido no georreferenciamento dessas ocorrências. Muito em breve, teremos séries temporais maiores, que poderão revelar tendência ou padrões mais constantes.

9. Somente para o ano de 2013, em termos de números absolutos, a SSP-AL registrou o percentual de $79,69 \%$ de crimes violentos letais intencionais praticados somente por arma de fogo e 1,77\%, por arma de fogo e arma branca. Dos homicídios ocorridos nesse mesmo ano, $11,8 \%$ foram praticados somente por arma branca e 4,60\%, por espancamento. 
mente homogêneo. A despeito das vicissitudes que explicam a "passagem ao ato", em situações que envolvem homicídios intencionais, os dados apontam uma explosão da violência homicida no estado e revelam um padrão: em regra, as vítimas são jovens negros ou pardos, de estratos menos favorecidos, mortos por arma de fogo, geralmente à noite, em áreas circunspectas e nos horários e dias de maior interação social. Um elemento surpresa: embora faltem informações mais detalhadas sobre o algoz, indícios sugerem que, em geral, este parece possuir um perfil bastante semelhante ao da vítima. Em outros termos, em Alagoas temos menos um genocídio, como já fora afirmado, até mesmo por institutos internacionais, e mais uma verdadeira "guerra" fratricida.

É interessante observar que, tal como mencionamos anteriormente, no que concerne às mortes causadas por fatores externos, Alagoas se diferencia da média nacional e regional no que diz respeito, exclusivamente, aos percentuais da violência homicida. Debruçando-se sobre o suplemento de violência da última Pesquisa Nacional por Amostra de Domicílios (Pnad, 2009) ${ }^{10}$ do Instituto Brasileiro de Geografia e Estatística (IBGE), podemos verificar que o padrão de agressões físicas, furtos e roubos em Alagoas, comparado às demais unidades da Federação, também não é significativo.

Na verdade, Alagoas é o estado com menor prevalência de agressões físicas de todo o país $(0,9)$, o que revela uma realidade no mínimo paradoxal, quando comparamos esse dado com as posições privilegiadas desse estado no ranking nacional da violência homicida. Levando-se em conta que é significativa a probabilidade de um homicídio ser antecedido, pelo menos, de uma agressão física, é curioso que a taxa de tais agressões, em Alagoas, seja tão baixa.

Indicadores dessa natureza nos fazem duvidar da hipótese segundo a qual a violência homicida seja explicada por uma cultura violenta própria do estado, como é fartamente realçado pela historiografia alagoana e pela mídia local. Não que Alagoas não seja conhecido, em um passado recente, pela prática desmedida da violência ligada a crimes políticos e de mando, bem como à proliferação de grupos de extermínio; contudo, acreditamos que a violência que estudamos hoje (e presenciamos na capital do estado e na RMM) transmutou-se em outra coisa. Tratamos de um fenômeno novo e diferente, no qual a cultura explica parte, mas não o todo. Manter a mesma an- tiga hipótese para o fenômeno novo é preencher de vinho novo um odre já gasto - precisamos ir além.

Outro ponto a ser destacado é o fato de que pelo menos $56,5 \%$ das agressões são cometidas por parentes ou cônjuges, ou mesmo por alguém conhecido, sendo que $28 \%$ delas ocorrem dentro das residências. Esses dados, e mais a constatação da relativa novidade do crescimento vertiginoso e sistemático dos homicídios no estado (1999), põem em xeque muito do que já foi dito sobre o crime de homicídio no estado, pois mostram que a taxa de letalidade em Alagoas pouco tem a ver com a ideia de um estado intrinsecamente violento ou com a predominância de uma cultura violenta de resolução de conflitos entre os alagoanos.

Nesse sentido, também é necessário investir esforços e recursos de pesquisa na verificação de outras hipóteses mais palpáveis para a causação do fenômeno, como a disseminação de drogas psicoativas e dos mercados ilegais, bem como a popularização das armas de fogo. Além, é claro, de estudos sobre o ordenamento socioespacial da cidade nas últimas décadas e a efetividade do sistema de justiça criminal no estado (Cerqueira, 2013).

Em relação aos crimes econômicos, tratando-se mais precisamente de roubos e furtos, Alagoas também não apresenta uma posição significativa, pois encontra-se na $19^{\mathrm{a}}$ e na $24^{\mathrm{a}}$ posição, respectivamente, entre as unidades da Federação com maior prevalência desses crimes. Assim, mais uma vez, ressaltamos que, do ponto de vista da prevalência, seja de crimes contra o patrimônio ou de crimes contra a pessoa, o único indicador que faz Alagoas destoar dos demais estados da Federação é o da violência homicida.

Todavia, resta-nos ainda indagar: por que um estado com índices tão altos de violência homicida apresenta percentuais relativamente baixos de roubos e furtos? Uma explicação possível e aceitável seria a baixa retribuição pelo roubo ou furto. Alagoas é o estado com a menor renda domiciliar per capita e a maior proporção de indivíduos abaixo da linha da pobreza no Brasil, o que deve reduzir os incentivos econômicos para se perpetrar tais crimes, visto que, na maioria das vezes, o ônus da ação pode ser maior que o bônus, ${ }^{11}$

Acreditamos que algumas respostas para essas aparentes contradições repousam sobre a relação entre a organização social do espaço urbano e a criminalidade violenta. Compreendemos que o modo e a forma pela qual se deu o processo de moderniza-

10. A Pnad do IBGE é uma pesquisa domiciliar padrão para todo o Brasil. Portanto, o indicador é perfeitamente comparável entre os diferentes estados brasileiros, não havendo aqui o tradicional problema nesta área, que é a subnotificação dos registros, levando-se em conta as diferenças procedimentais de registro policial no Brasil.

11. Em breve, com o georreferenciamento dos roubos e furtos cometidos na cidade de Maceió e sua RM, poderemos mapear as áreas de maior vulnerabilidade a roubos e furtos na região, o que, provavelmente, corroborará nossa ideia de que estes tipos de crime também têm seu local de influência e ocorrência na cidade. 
ção e urbanização das cidades e capitais brasileiras, a exemplo de Maceió, são fundamentais para se entender, hoje, a incidência de tão negativos indicadores de violência homicida. Há, neste caso, que se considerar outras taxas igualmente importantes, como o grau de urbanização; os percentuais de migração rural-urbana e seu impacto sobre a economia local; a densidade populacional; a incapacidade do estado de prover serviços sociais básicos como saúde, educação e transporte público; a segregação urbana e o apartheid social; a pobreza e a desigualdade; o crime organizado e o tráfico de drogas.

Ou seja, é preciso explicar como e por que o controle social foi perdido ou enfraquecido no tecido urbano da cidade de Maceió e na RMM. Nesse sentido, os estudos sobre a dinâmica dos homicídios são essenciais, tanto para o diagnóstico de tendências da criminalidade quanto para a formulação (e subsequente monitoramento) de estratégias de controle e prevenção adequadas às particularidades locais e regionais. ${ }^{12}$

\section{A construção social do crime em Alagoas: um esboço de interpretação}

O problema da violência em Alagoas foi pouco atacado porque ainda pouco se conhece dele. Pouco sabemos dos meios objetivos para atacá-lo porque pouco sabemos de suas causas, somente conhecemos os seus efeitos. É nesse sentido que afirmamos ter a discussão sobre homicídios em Maceió reforçado hipóteses nebulosas e pouco factíveis, como a ideia de que tal estado de caos é produto residual da trajetória histórica do estado, consequência dos indicadores sociais locais negativos (hipótese fartamente contestada pela literatura especializada no Brasil desde os idos de 1980) ou, ainda, reflexo de uma espécie de ethos violento (o alagoano, diferente de outros tipos, teria uma tradição intrínseca de resolver conflitos por meio da violência).

Rejeitamos essas perspectivas. Acreditamos que é preciso esmiuçar o fenômeno sem perder de vista algumas evidências empíricas importantes. É preciso conhecer a tessitura por trás dos eventos criminais. Nesse sentido, propomos uma apropriação analítica das proposições de Misse (1999, 2002, 2006, 2008a, 2008b, 2010), no sentido de superar os limites de explicações historicistas ou culturalistas para o problema da violência homicida em Alagoas. Talhados a princípio para o contexto da violência urbana cario- ca, os conceitos do autor enfatizam a autonomia do social sobre a cultura e sobre as instituições ou a história (sem também desprezar estas variáveis no conjunto da análise), propondo um giro no conjunto das explicações desenvolvidas para o estudo da violência, sem perder de vista algum poder de generalização.

A constituição dos conceitos de acumulação social da violência e sujeição criminal, ainda que estruturados a partir da experiência do Rio de Janeiro e sua região metropolitana, não excluem a possibilidade de sua validade para a interpretação do problema da violência em outras cidades, capitais ou estados brasileiros - com as devidas ressalvas, naturalmente. Entendida como um processo social lento, a ideia de acumulação social da violência faz uso de demarcações e delimitações históricas, chamando nossa atenção para a complexidade causal do fenômeno e sua dimensão mais cumulativa e menos residual (Misse,1999, 2008a). O que possibilita ao analista superar eventuais tautologias, como, no caso alagoano, a miopia analítica que impede grande parte dos estudiosos da temática de identificar e interpretar as transformações em torno da prática e dos significados da violência na região.

Seja pelo que é dito ou produzido na academia, seja pelo que constitui o senso comum das pessoas acerca do fenômeno, predomina em Alagoas o consenso quase generalizado de que a violência do estado é produto residual de raízes históricas. Um número farto de casos de violência histórica são arrolados como prova de uma violência mítica e fundante, à qual Alagoas estaria predestinada. Servem a esta intuição superficial de interpretação do problema o extermínio dos quilombolas de Palmares no século XVIII, a violência fundante da província no século XIX, os registros de passagem do cangaço e do banditismo rural, a perseguição histórica aos terreiros de candomblé nos anos iniciais da República, a memória recente dos grupos de extermínio que ocuparam a mídia nacional nos idos dos anos de 1980, ou mesmo a alusão a casos menos conhecidos da história local, como o impeachment do governado Muniz Falcão, que selou uma sucessiva onda de crimes de mando na região.

O crime de homicídio em Alagoas, embora a cada dia naturalize-se mais e mais para a população local, dado o seu crescimento sistemático, apresenta-se como um fenômeno relativamente recente, pelo menos no que diz respeito ao seu volume. Somente nas duas últimas décadas o estado tem apresentado patamares crescentes de violência homicida, e seus percentuais para causas externas de mortalidade, nos períodos históricos anteriores, são similares aos da região Nordeste. A despeito da crença generalizada

12. Segundo dados da SSP-AL, os bairros do Benedito Bentes, Jacintinho, Santa Lúcia, Tabuleiro dos Martins e Vergel apresentam as maiores taxas de violência homicida no município de Maceió. 
de que muito se sabe sobre o problema, na verdade sabemos pouco, e menos ainda sobre as diversas facetas do fenômeno, o que tem impactado diretamente na ineficiência do estado em definir políticas públicas de segurança. Afinal, não há estratégias eficazes para driblar um problema que pouco conhecemos.

De forma irregular e nada contínua, o estado tem acenado com uma sucessão de experiências pouco exitosas de implementação de políticas, programas e projetos de segurança pública, cada qual responsável por lançar uma nova tábua de salvação - o enfrentamento do crime organizado, a criação de bases de polícia de proximidade, o investimento em ações de policiamento ostensivo para áreas críticas, o combate ao tráfico de drogas e até mesmo a extensão de políticas terapêuticas de recuperação. Acredita-se que essa ausência de linearidade na ação do estado seja também, em alguma medida, resultado desse vácuo analítico; afinal, os gestores pouco sabem por onde começar. Todavia, embora saibam que não podem transformar a realidade social de uma hora para outra, eles precisam responder aos clamores sociais, tendo em vista que pessoas continuam sendo mortas no estado a cada dia.

A partir da proposição misseana, reintegramos a variável história - de forma cumulativa, todavia, dinâmica - à análise do fenômeno. Primeiramente, é necessário desmistificar a experiência histórica alagoana como se fosse algo absolutamente distante ou incompatível com a de outros estados próximos ou vizinhos; afinal, o cangaço, o mandonismo político, a violência escravista sobre os povos de matriz africana e a constituição de grupos de extermínio não foram "privilégios" exclusivamente alagoanos. Considerar a violência urbana atual em Alagoas, sobretudo a violência homicida, como produto residual desse passado é desprezar o próprio objeto da nossa investigação: a disseminação e as transformações da criminalidade violenta contemporânea.

A ausência de clareza sobre o "inimigo" a ser enfrentado tem, na verdade, ao seu modo, selecionado os potenciais inimigos da sociedade alagoana: aqueles que se acredita "potencialmente" violentos e quase "predestinados" ao crime. Os meandros da ideia de uma espécie de sujeição criminal reforçam, em Alagoas, menos a antecipação preventiva da criminação pelas vias extralegais, como fartamente discutido e apontado pela literatura especializada (Misse, 2002, 2008b; Vargas; Rodrigues, 2011), e mais a ideia de uma condenação à própria sorte.

No caso observado pelos autores para o Rio de Janeiro, o "potencial" criminoso é diretamente acusado, mesmo antes que qualquer evento tenha sido "criminado", o que provoca uma transformação substancial, sobretudo para os aparelhos de segurança do Estado: o deslocamento do evento para o sujeito, ou seja, do crime para o virtual criminoso. A estigmatização social destes "tipos" aqui não se restringirão somente à imputação de rótulos desacreditados de identidade social (Goffman, 2012; Becker, 2008); na verdade, ela vai mais além. Ela funda evento e autor antes mesmo que qualquer coisa tenha ocorrido, e entender-se-á que o sujeito carrega em si a propensão ao crime. Será o sujeito culpado antes de qualquer coisa.

Não é por outro propósito, se não por esta complexa rede de imputação subjetiva, que a polícia carioca vem acumulando indicadores expressivos de baixas categorizadas agora como resistência seguida de morte, para referir-se às mortes cometidas por policias em confronto com comunidades ditas violentas. Este pressuposto nega a existência da possibilidade da liberdade de escolher entre cometer ou não cometer o crime, e criminaliza/incrimina/condena o potencial criminoso por antecipação. O crime seria algo intrínseco a esses sujeitos, portanto, sua ressocialização seria algo praticamente impossível.

Nesse sentido, os representantes da lei podem reconhecer-se moralmente superiores a esses e, por conseguinte, antecipar-lhes a pena. Este estado de coisas está também relacionado à própria dinâmica urbana da cidade - no caso carioca, o potencial inimigo é visível, "incomoda" e está à vista de todos, moradores e visitantes. No caso de Alagoas, não. Sugerimos pensar que, ao seu modo, no contexto do Rio de Janeiro, a sujeição criminal viola os princípios da incriminação racional-legal e solapa as bases do que se presume um Estado democrático de direito todavia, há ali um sujeito. Diríamos, se compararmos as situações, que no Rio há o indivíduo e falta-lhe o direito, mas em Alagoas, faltam ambos.

O processo de urbanização que a cidade de $\mathrm{Ma}-$ ceió e as demais cidades da sua região metropolitana atravessaram, a partir da década de 1970, provocou transformações significativas nas dinâmicas de ocupação do espaço e de socialização. Diferentemente de outras capitais brasileiras de médio e grande porte, em que os bolsões de pobreza e miséria convivem paralelamente com áreas nobres da cidade, em Maceió os espaços urbanos respeitam uma demarcação invisível, mas não menos importante. Como pode ser visto nos mapas temáticos anteriormente apresentados, a explosão da violência homicida em Alagoas concentra-se em áreas circunscritas e muito precisas. Há até mesmo a situação pouco comum de ruas que concentram as taxas de homicídios de todo um bairro.

O que há de comum entre essas áreas e seus bolsões mais críticos é que estão distantes das áreas nobres, turísticas, e dos bairros familiares de classe média. Maceió, grosso modo, opera como uma cidade dentro de outra cidade. De maneira geral, as áreas que hoje concentram as cifras homicidas de Maceió e sua 
região metropolitana são áreas de ocupação recente, com a migração de populações oriundas da zona rural e das cidades do interior, as quais sofreram um processo intenso de evacuação nas décadas de $1970 \mathrm{e}$ 1980, a partir da crise da indústria sucroalcooleira e das inúmeras remoções de comunidades inteiras, promovidas pelo governo do estado a partir de um intenso processo de higienização social nesse período.

$\mathrm{Na}$ segregação invisível, mas tangível, da cidade os crimes respeitam limites territoriais. Não há incidência relevante de crimes de homicídio na área nobre e litorânea de Maceió. Para esta área estão restritos os crimes de menor porte, como furtos e crimes patrimoniais, os quais também não se destacam, como já dissemos, dos crimes de mesma natureza nas demais capitais da região Nordeste. Não obstante, Alagoas, especialmente Maceió, tem uma peculiaridade habitacional - as chamadas grotas.

As grotas são áreas caracterizadas por depressões profundas, amplamente utilizadas para moradia, constituindo verdadeiros conglomerados irregulares e disformes, distantes de qualquer tipo de organização ou planejamento. Não há, na maioria das grotas, acesso à rede de coleta de esgoto ou fossas sépticas, nem abastecimento de água ou coleta de lixo. São nessas áreas, ou nas suas proximidades, que se concentram boa parte dos registros de violência homicida do estado. ${ }^{13}$

Os morros são íngremes e não há como se recusar a vê-los, pois estes, de alguma forma, acomodam-se à cidade. Há a presença constante da sua existência no registro visual diário. As grotas, ao contrário, são invisíveis. São imperceptíveis mesmo ao visitante mais atento, pois, literalmente, "escondem" a população embaixo dos vales e paredões. E para as populações que habitam nessas condições subnormais, resta muito pouco - falta-lhes, até mesmo, o acesso a garantias fundamentais, como documentos de registro, ${ }^{14}$ ou a existência de um endereço postal, que lhes garantiria o acesso a benefícios populares ou a conquista de um posto de trabalho, ainda que precário.

Não fora suficiente, falta a estes sujeitos, sobretudo, antes da cobertura legal do direito, o seu reconhecimento enquanto pessoas de direito. Em outras palavras, se compararmos tais dinâmicas entre o Rio de Janeiro e Maceió, poderemos observar que, se numa cidade a vida de uns vale muito pouco porque muitos lhe são indiferentes, na outra não há sequer a indiferença contra o outro, porque a existência do indivíduo é sumariamente desconsiderada. Assim é Alagoas: a indignação com o assassinato restringe-se à prática do crime em áreas circunscritas da cidade, onde a lógica da razoabilidade faz sentido.

Partindo do conceito de sujeição criminal, buscamos aprofundar essa percepção de negação do "valor-fonte" da pessoa humana de modo a compreendermos uma situação particularmente atípica. Tratamos aqui, no caso de Alagoas, de uma situação em que podemos acusar a constituição de uma massa flutuante de sujeitos, aquém dos direitos básicos de cidadania e largados à própria sorte. Fora sobre situações desse tipo (geradas no bojo da própria modernidade e como desdobramento não esperado dos seus valores) que Arendt $(2000 ; 2003)$ refletira, quando explicitara a convicção de que o fundamento último da legitimidade da ordem jurídica instituída pelo Direito Natural entrara em crise a partir da modernidade, e agora inauguraríamos a existência de organizações sociais nas quais a existência de seres humanos poderia tornar-se supérflua - na verdade, seriam seres descartáveis (ex parte populi).

A esses sujeitos de nada vale quaisquer critérios razoáveis de Justiça, pois lhe é vedado o acesso à construção do mundo comum. A perda da cidadania, compreendida por Arendt como o direito a ter direitos, é compreendida aqui como a privação do estatuto político do sujeito, que agora torna-se "apenas um ser humano", privado de suas qualidades substanciais e "impossibilitado de habitar um mundo compartilhado"; logo, incapaz de "ser tratado pelos outros como um semelhante" (Arendt, 2000).

A ruptura do direito fundamental de que trata Arendt é conseguida, na prática, pelo isolamento, que destrói em essência a possibilidade da vida pública considerando-se, em sentido arendtiano, que ser visto e ouvido é parte constituinte fundamental do estar no mundo. Desta forma, o que dissemos sobre a lógica do habitar e sobre a dinâmica espacial da cidade é uma pista sui generis para uma compreensão mais profunda das dinâmicas que operam sob os modelos e os padrões de sociabilidade da cidade, de maneira geral, mas, especialmente, das áreas que concentram os percentuais mais altos de violência homicida.

13. No andamento das nossas entrevistas, a imagem da grota é recorrente entre agentes da segurança pública, sejam os policiais militares (que temem a grota por considerá-la uma potencial armadilha para a ação policial; os policiais sentem-se vulneráveis ao "descer" a grota, pois receiam tornar-se alvos fáceis de ser alvejados a partir das encostas), seja entre os agentes da polícia civil (inúmeros processos acabam por ser arquivados quando os possíveis culpados são moradores de grotas, pois tratamos aqui de uma dinâmica habitacional não prevista para o sistema de justiça criminal, visto que não há vizinhança regular, não há ruas, nem números de registro para as habitações; na verdade, as próprias casas apresentam uma conformação diferenciada que carece de reflexão socioantropológica sobre os limites do habitar).

14. Atualmente, o percentual de crianças sem registro, segundo dados do IBGE para Alagoas, é de 13,4\%, enquanto a média nacional é de $6,7 \%$. Ressalte-se que, embora o percentual alagoano seja praticamente o dobro da média nacional, há 10 anos esse percentual no estado chegou a 53\%, quando Alagoas ocupou a terceira posição no ranking nacional de sub-registro de crianças. 
Faltam ainda, em Alagoas, estudos que explorem as suposições do comportamento desviante para além do que seja considerável razoável aos contextos normativos definidos. É preciso explorarmos as peculiaridades em torno das transformações das práticas de violência no estado, para além, inclusive, de quaisquer perspectivas meramente exteriorizadas. Nesse sentido, temos aprofundado nossas pesquisas nas transformações em torno da própria violência urbana que encontramos hoje em Maceió - a qual julgamos credora de um passado, mas igualmente nova e autônoma - e no hiato que as transformações relativamente recentes da cidade têm trazido para os novos padrões de sociabilidade que se formam e se conformam nas áreas periféricas da cidade; com foco, sobretudo, na dinâmica da sociabilidade juvenil, tendo em vista que os jovens têm sido, em sua grande maioria $(82 \%)$, as principais vítimas de homicídio no estado.

Encontramos em Alagoas, mais precisamente em Maceió, uma forma radicalmente nova de organização das relações sociais, diferente de tudo que a cidade tenha experimentado antes e que transformou substancialmente as dinâmicas de sociabilidade da região. A cidade é hoje, acima de tudo, uma cidade cindida. Apartada por indicadores sociais negativos e pela explosão perversa do fenômeno da violência homicida, que reforça as barreiras intransponíveis entre os que podem e os que não podem integrar a cidade em sua plenitude. Há, na prática, duas cidades: a dos que são vistos e a dos que não o são; os invisíveis, os esquecidos. É sobre esses últimos que devemos voltar nossa atenção de pesquisadores.

\section{Conclusão}

"Explicação" e "intervenção" são temas estreitamente vinculados em segurança pública. A compreensão da dinâmica da estruturação dos grupos em diferentes graus de organização dá-se, principalmente, com a compreensão da forma de organização do espaço urbano, observando-se o desenvolvimento de mecanismos de controle social ou a ausência deles nesses territórios. Nesse sentido, acredita-se que uma melhor compreensão do fenômeno da violência urbana, bem como da dinâmica dos homicídios no espaço urbano de Maceió e na sua região metropolitana, facilitará o desenvolvimento de projetos de intervenção decisivos para o controle de seus percentuais.

Os dados mostram que não há uma situação congênita de violência no estado de Alagoas. Há, sim, uma endemia de homicídios, mas não de agressões físicas, nem de crimes economicamente motivados. O fato de estes percentuais tomarem maior envergadura a partir das duas últimas décadas realça a necessidade de pesquisas sobre fatores ocorridos nesse período. Com isso, não queremos fazer tábula rasa do acúmulo social dos vários problemas que acometem a população alagoana, mas tão somente enfatizar que, considerando o comportamento da taxa de homicídio do estado ao longo desse período, pode-se dizer que, embora o fenômeno dos homicídios possa tornar-se cada vez mais crônico, ${ }^{15}$ impondo desafios às políticas públicas e às ações da sociedade civil, seu volume e sua extensão são relativamente recentes.

É preciso conhecer melhor o fenômeno para poder atacá-lo. Em outras palavras: sem "explicação", não há "intervenção". Em linhas gerais, essa dimensão é importante não somente para Alagoas, mas para todo o Brasil, pois muitos projetos de segurança pública aplicados por todo o território nacional têm se pautado mais por pressupostos de conteúdo impressionista, político ou ideológico, e menos pela racionalização do fenômeno e por políticas preventivas coerentes e verificáveis.

É necessário que as discussões que orientam a ação de Estado e a gestão pública sejam amparadas por forte base teórica e conceitual para dar-lhes sustentação; por isso mesmo, necessitamos também investir em um enfoque que possa oferecer um conhecimento sólido e aplicável e uma base empírica para generalizações que possam subsidiar pesquisadores e policymakers. 


\section{Referências}

APRATTO, Douglas. A tragédia do populismo. Maceió: Edufal, 2007.

ARENDT, Hannah. A condição humana. Rio de Janeiro: Forense Universitária, 2000.

ARENDT, Hannah. Eichman em Jerusalém - um relato sobre a banalidade do mal. São Paulo: Companhia das Letras, 2003.

BEATO, C. Crime e cidades. Belo Horizonte: Ed. UFMG, 2012.

BECKER, Howard S. Outsiders. Rio de Janeiro: Zahar, 2008.

BRASIL. Ministério da Saúde. Datasus. Disponível em: $<$ http://www2.datasus.gov.br/DATASUS/index.php>.

CARVALHO, Cícero Péricles de. Economia popular - uma via de modernização para Alagoas. Maceió: Edufal, 2012. CERQUEIRA, D. R. C. Causas e consequências do crime no Brasil. 2010. Tese (Doutorado em Economia) - Pontifícia Universidade Católica do Rio de Janeiro, Rio de Janeiro, 2010.

CERQUEIRA, D. R. C. Por um plano integrado "Maceió é de paz!". In: SILVA, Alexandre Manoel A. (Org.). Economia de Maceió: diagnóstico e proposta para construção de uma nova realidade. Maceió: Edufal, 2013. CRUZ, M. V.; BATITUCCI, E. C. (Org.). Homicídios no Brasil. Rio de Janeiro: Editora FGV, 2007.

FREITAS, Geovani J.; MELLO, Paulo D. A.; ALMEIDA, Rosemary de O. As organizações policiais em revista. São Paulo: Pontes Editores, 2009.

FÓRUM BRASILEIRO DE SEGURANÇA PÚBLICA. Anuário Brasileiro de Segurança Pública , 2015. Disponível em: <http://www2.forumseguranca.org.br/>.

GOFFMAN, Erving. Estigma: notas sobre a manipulação da identidade deteriorada. Rio de Janeiro: LTC, 2012.

LINDOSO, Dirceu A. Uma cultura em questão: a alagoana. Maceió: Edufal, 1981.

LINDOSO, Dirceu A. Formação de Alagoas Boreal. Maceió: Edições Cata-Vento, 2000.

LINDOSO, Dirceu A. Interpretação da província: estudo da cultura alagoana. Maceió: Edufal/Seplan/Fundação Manoel Lisboa, 2005.
MANSO, B. P. Crescimento e queda dos homicídios em São Paulo entre 1960 e 2010. Uma análise dos mecanismos da escolha homicida e das carreiras do crime. 2012. Tese (Doutorado em Ciência Política) - Faculdade de Filosofia, Letras e Ciências Humanas, São Paulo, 2012.

MISSE, Michel. Malandros, marginais e vagabundos - a acumulação social da violência no Rio de Janeiro. 1999. Tese (Doutorado em Sociologia) - Instituto Universitário de Pesquisas do Rio de Janeiro, Rio de Janeiro, 1999.

MISSE, Michel (Org.). Acusados \& acusadores - estudos sobre ofensas, acusações e incriminações. Rio de Janeiro: Revan, 2008a.

MISSE, Michel. Sobre a acumulação social da violência no Rio de Janeiro. Civitas, Porto Alegre, v. 8, n. 3, p. 371385, set.-dez. 2008b.

MISSE, Michel. Tradições do banditismo urbano no Rio: invenção ou acumulação social? In: MISSE, Michel. Crime e violência no Brasil contemporâneo. Rio de Janeiro: Lumen Juris, 2009.

MISSE, Michel. Crime e violência no Brasil contemporâneo. Rio de Janeiro: Lumen Juris, 2010.

SOARES, G. A. D. Não matarás. Desenvolvimento, desigualdade e homicídios. Rio de Janeiro: Editora FGV, 2008.

VERÇOSA, E. G. Cultura e educação nas Alagoas: história, histórias. Maceió: Secretaria de Educação de Alagoas, 2001.

VARGAS, Joana D.; RODRIGUES, Juliana N. L. Controle e cerimônia: o inquérito policial em um sistema de justiça criminal frouxamente ajustado. Sociedade $e$ Estado, Brasília, v. 26, n. 1, p. 77-96, jan.-abr. 2011.

ZALUAR, A. Condomínio do diabo. Rio de Janeiro: Editora UFRJ, 1994.

ZANOTELLI, C. Desterritorialização da violência no capitalismo globalitário: o caso do Brasil e do Espírito Santo. Revista Terra Livre, São Paulo, v. 2, n. 21, p. $225-$ $240,2003$. 


\title{
Transformations around the phenomenon of violence homicide in the state of Alagoas
}

\begin{abstract}
Although Alagoas state occupy most violent position in Brazil since 2006 few efforts have been made in order to explain and understand the constitution this reality. The explosion of percentage of homicidal violence registered in Alagoas in the last decade has been often associated, sometimes the idea of a historical residue of violence "founding" of the province in century XIX or the idea of a culture of violence that distinguish the alagoano" other types. We believe that these arguments lose the particularity of problem because draft too much structuralist explanations that through the time over contributed little to the formation of cognitive components that foment the design and implementation of plans or security programs in the state. We use here the concepts of social accumulation of violence and criminal subjection in order to reaffirm the creation of an interpretation less historicist and more sociological that phenomenon. We argue that in Alagoas case this process has spread, perhaps as nowhere else in Brazil, the production of a speech overlooking - the symbolic and practical level of state relations - the development of preventive or compensatory public security policies .
\end{abstract}

Keywords: social accumulation of violence, criminal subjection, homicide, Alagoas.

\section{Modificaciones alrededor de la violencia asesina en el estado de Alagoas}

\section{Resumen}

A pesar de que Alagoas ocupa la posición de estado más violento de Brasil desde el año 2006, pocos esfuerzos se han hecho para explicar y comprender la constitución de esta realidad. El aumento de porcentajes de la violencia homicida registrada en Alagoas en la última década ha sido con frecuencia asociada o a la idea de un residuo histórico de la violencia "fundadora" del estado en el siglo XIX, o a la idea de una cultura de la violencia que distinguiría especialmente al alagoano.

Creemos que estos argumentos pierden de vista la particularidad del problema, pues enfatizan explicaciones estructuralistas que, a lo largo del tiempo, poco contribuyeron a la formación de componentes cognitivos que fomentaran la concepción y la implementación de planes o programas de seguridad en el estado. Recurrimos aquí a los conceptos de acumulación social de la violencia y sujeción penal, de modo a reafirmar la constitución de una interpretación menos historicista y más sociológica del referido fenómeno. Se argumenta, además, que, en el caso de Alagoas, este proceso ha diseminado, quizá como en ningún otro lugar en Brasil, la producción de un discurso que es negligente, en los planos simbólico y práctico de las relaciones de Estado, con el desarrollo de políticas públicas de seguridad preventivas o compensatorias.

Palabras clave: acumulación social de la violencia, sujeción criminal, homicidios, Alagoas.

Data de recebimento do artigo: 05/ 2016 Data de aprovação do artigo: 11/2016 
